\title{
Analysis of Date Water Toner to Brighten Dry Facial Skin
}

\author{
Novia Restu Windayani ${ }^{1, *}$ Octaverina Kecvara Pritasari ${ }^{1}$ \\ ${ }^{1}$ Cosmetology Education Departement, Universitas Negeri Surabaya \\ *Corresponding author. Email: noviawindayani@unesa.ac.id
}

\begin{abstract}
There are various kinds of facial skin, one of which is a problem for mothers with dry skin due to hyperpigmentation that appears and wrinkles on the face. Dates used in making toners are ajwa dates because they have less sugar content than other types of dates, making them easier in the manufacturing process. The purpose of research on antioxidants and vitamin $\mathrm{C}$ in date water toner products and analysis of date water toner for dry facial skin in terms of sensory tests, preference tests, and clinical trials. The method used is the experimental method. The results of the date water toner on the sensory test were declared very feasible with an average of $73.33 \%$. The preference test was stated to be very like with an average of $76.66 \%$. The results of clinical trials were declared very feasible with an average of $85.24 \%$. The conclusions of this study are based on the results of lab tests with the results of $235,327 \mathrm{mg} / 1000 \mathrm{mg}$ of vitamin $\mathrm{C}$ and $20,096 \mathrm{mg} / \mathrm{mL}$ of antioxidants, sensory tests were stated to be very feasible, the results of the preference test were stated to be very favorable, and the results of clinical trials showed a change in facial skin brightness. Suggestions for this research are for experts and practitioners in the field of cosmetology to be more creative and innovative in utilizing natural ingredients to be used as beauty products, to educators in the field of cosmetology to be an example in the teaching system of entrepreneurship, cosmetic chemistry, and cosmetology courses, in the industrial world diversification for natural toner products to create natural beauty products.
\end{abstract}

Keywords: water toner, brighten dry, facial skin

\section{INTRODUCTION}

Dates used in making toners are dates because they have less sugar content than other types of dates, making them easier in the manufacturing process. In addition, dates contain high levels of vitamin $\mathrm{C}$ and antioxidants, which can help to brighten dull facial in science. Dates are fruits that have high antioxidants. Antioxidant testing was carried out at two levels of ripe dates, namely ripe and half-ripe dates using the DPPH test method, giving the results that the average antioxidant activity at the level of half-ripe dates was $107.5 \mathrm{~mol}$ TEAC/100g dry material, dry $2500 \mathrm{mg}$.

One of the cosmetics used by the public in the presence of toner, to be able to remove dirt and close pores. Based on the Regulation of the Minister of the Republic of Indonesia, cosmetics are divided into parts, namely, cosmetics for babies such as baby oil and baby powder, cosmetics for bathing, namely bath soap and shampoo, cosmetics for the eyes. Traditional cosmetics are natural cosmetics or original cosmetics that can be made directly from fresh or dried ingredients, fruits, or plants [1]. Traditional cosmetics are homemade cosmetics that are processed from plants that grow around, which are still fresh or have been preserved. The advantage of traditional cosmetics is that it has fewer side effects because it does not add chemicals and is also cheaper.

Dull skin conditions are common in dry skin types because the outer layer of skin peels off and accumulates. This skin condition, makes facial skin look more dull, scaly, easy to peel, and looks wrinkled due to invisible pores. In addition to dry skin types, dull skin conditions can also occur in other skin types. Some of the factors that cause dull skin include the use of the wrong products, air pollution, unhealthy lifestyles, and stress. The human body has a regeneration mechanism for the skin, or in other words, the body can restore dull skin to be fresh and beautiful again. According to [2], the skin needs time to regenerate for $14-28$ days. However, in this study, the face toner formula used natural ingredients, namely dates, which contained the same benefits as the face toner 
formula, namely vitamin $\mathrm{C}$ and antioxidants to brighten facial skin and ward off free radicals. According to [3]. preparations must have the appropriate aroma requirements, clear colors, liquid textures and do not give a sticky impression, and give a fresh impression on the skin. The purpose of research on antioxidants and vitamin $\mathrm{C}$ in date water toner products and the feasibility of date water toner to brighten dull facial skin in terms of sensory tests, preference tests, and clinical trials.

An aroma is a form of olfactory technique using the nose interest of clients or the public. The color of the date water toner is influenced by the brown flesh of the dates. The requirements for toner preparations must be clear, not cloudy. Toner preparations must have a liquid texture and do not cause a sticky impression on the face when used. The fresh impression and absorption of cosmetics at the first use are quite important assessments in assessing preferences for the impression of use [4]. The sensitivity indicator uses an open patch test technique or a patch test which is carried out by applying the test preparation to normal human skin to know whether the reaction to the preparation can cause skin irritation or not.

\section{METHOD}

In research using quantitative-based philosophy using population and sample., sampling techniques are generally carried out randomly, data collection uses research instruments, data analysis is quantitative/statistical. to test the established hypothesis. Research methods used, experimental methods Selecting a subject as many as 15 people according to the criteria, namely respondents who have dry skin criteria. Subjects considered to be the treatment group (X) Provide a Pre Test assessment to measure the amount of dullness and hair length in the treatment group (X). Maintaining all conditions for the treatment group (X) within a predetermined period of 4 treatments. Giving Post Test assessment to the treatment group (X) to measure the dependent variable. Calculate the average test results after treatment in the treatment group (X) to determine its effectiveness. A research variable is an attribute or nature or value of a person, object, or activity that has a certain variation determined by the researcher to be studied and then drawn conclusions. The variable used in the research that relates to data collection in this study is a single variable. The single variable in this study was toner using date water from mothers in the Pagesangan Asri area with a total of 15 women. The object of this research is date water toner

The questionnaire contains written questions given to the panelists who are willing to give a response about the toner product that will be applied to the client's facial skin. This instrument is used to collect toner product feasibility test data which includes sensory test, preference test, and clinical test of date water toner[5][6]. academics in the field of beauty, 2 pharmacists who are knowledgeable in toner cosmetics.

\section{1. Sensory Test}

Sensory tests are used to determine the effect of the quality of each toner sample which includes indicators of viscosity, color, aroma, and texture on the toner which is assessed by the three experts by bringing one respondent/model to assess the ease of application and using 4 quality classifications with the highest score of 4 and the lowest score is 1 .

\section{2. Preference Test}

The preference test in this study, the panelists used were 10 panelists who were mothers with dry facial skin to assess the products that had been made by the researchers to determine the level of preference for the experimental toner products. In this preference, the test uses color, aroma, texture, first impression of use, and sensitivity.

\section{3. Clinical trial}

Clinical trials were conducted to determine the effectiveness of toner for dull facial skin from date water. How to observe changes/reductions in the dullness of the face can be seen from the number indicator. This clinical trial was conducted to determine the effect of using date water toner on dry skin for 4 weeks. This clinical trial was conducted by 3 trained panelists who work as doctors and facial therapists to assess the brightness of the respondents' facial skin. Assessment of clinical trials using a skin color rating tool from Fair and lovely products PT.

Data analysis is the process of systematically searching and compiling data obtained from interviews, field notes, and documentation, by organizing the data into categories, describing them into units, synthesizing, compiling into patterns, choosing which ones are important and which ones will be. learned and make conclusions so that they are easily understood by themselves and others[7][8]. Data analysis is carried out systematically so that research results can be justified scientifically. The analysis in this study used a descriptive percentage analysis.

\section{RESULT AND DISCUSSION}

Results of Laboratory Tests of Date Water as a Dry Skin Toner Laboratory results for date water used to lighten dry skin, tested in the laboratory of the biology department of Semarang State University which has been tested on April 5, 2021. Table 1 states the statement of the results of laboratory tests at the Lab majoring in biology, State University of Semarang, with the results of date water toner on vitamin $\mathrm{C}$ with results of 235,327 $\mathrm{mg} / 1000 \mathrm{mg}$ and total antioxidant status with results of $20,096 \mathrm{mg} / \mathrm{mL}$. 
Table 1 Results of Date Water Toner Analysis

\begin{tabular}{|l|l|l|}
\hline $\begin{array}{l}\text { Sample } \\
\text { Code }\end{array}$ & $\begin{array}{c}\text { Vitamin C } \\
(\mathrm{mg} / 1000 \mathrm{mg})\end{array}$ & $\begin{array}{c}\text { Total } \\
\text { Antioxidant } \\
\text { Status } \\
(\mathrm{mg})\end{array}$ \\
\hline $\begin{array}{l}\text { Water } \\
\text { toner }\end{array}$ & 235,327 & 20,096 \\
\hline
\end{tabular}

In this case, date palm water toner has properties in the skin in addition to dull skin but is also efficacious in beauty, including preventing the appearance of redness on the skin due to irritation, preventing premature aging, overcoming hair loss, and maintaining healthy hair.

The sensory test research used 3 expert panelists, in the assessment, namely by observing the toner product using date water as a base material from a sensory point of view. The sensory test assessment was carried out by 3 expert panelists, namely 1 beauty academic, and 2 pharmacists.

Table 2 Sensory Test Results of Dates Water as Toner Brighten Dry Skin

\begin{tabular}{|l|l|}
\hline & \multicolumn{1}{|c|}{ Presentase } \\
\hline Riuzkiana & $73,33 \%$ \\
\hline Drisnakana & $80,66 \%$ \\
\hline Yunaini & $75,00 \%$ \\
\hline Total Average & $76,33 \%$ \\
\hline Criteria & Match \\
\hline
\end{tabular}

In Table 2, the research data has been produced, namely toner products that lighten dull skin using date water are described according to each panelist, panelist 1 obtained an average value of $73.33 \%$, the criteria were very suitable, for panelist 2 obtained $80.66 \%$ very suitable criteria and panelist 3 also obtained a score of $75.00 \%$ with very suitable criteria in this case obtaining an average of $76.33 \%$ declared very suitable or feasible.

The preference test study used 20 moderately trained panelists, namely mothers who applied cosmetic toner to brighten dry skin, to determine the value of preference for toner products using date water.

Based on the research data of the preference test above, it can be stated that a toner product to brighten dull skin using dates water as the basis for the criteria is very like because it has a total average of $86.66 \%$ with a description of the indicator having a color percentage of $100 \%$, the criteria are very like, the aroma is $68.00 \%$ with criteria quite like, texture $88.00 \%$ having criteria like very much, impression using toner 92.00 has criteria like very much, impression after using a toner is $84.00 \%$ with criteria like very much and sensitivity $85.00 \%$.

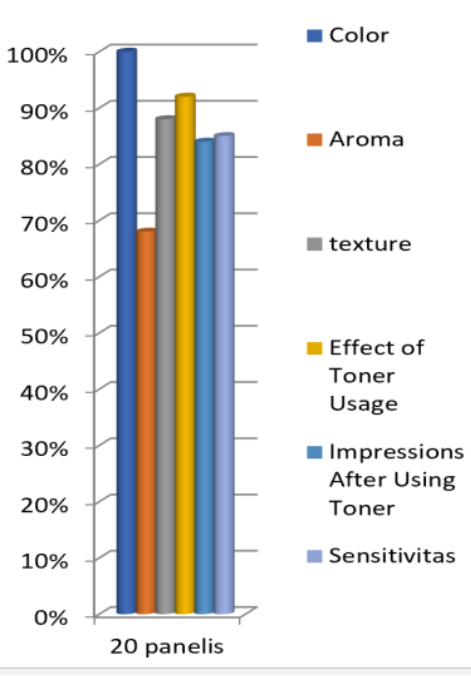

Figure 1. Data on the Test Results of Dates Water Preference as Toner for Brighten Dry Skin

Based on the research data of the preference test above, it can be stated that a toner product to brighten dull skin using dates water as the basis for the criteria is very like because it has a total average of $86.66 \%$ with a description of the indicator having a color percentage of $100 \%$, the criteria are very like, the aroma is $68.00 \%$ with criteria quite like, texture $88.00 \%$ having criteria like very much, impression using toner 92.00 has criteria like very much, impression after using a toner is $84.00 \%$ with criteria like very much and sensitivity $85.00 \%$.

The clinical trial research used 3 expert panelists, namely 2 skincare doctors, and 1 facial therapist who applied cosmetic toner to brighten dull skin based on date water on the client's dull face, to determine the clinical value of toner products brightening dull skin by using date water, to guarantee the certainty of the benefits of toner products that function to brighten dry skin.

Table 3 Data on Clinical Test Results in Dates Water as a Toner to Brighten Dry Skin

\begin{tabular}{|c|l|l|r|}
\hline No & \multicolumn{1}{|c|}{$\begin{array}{c}\text { Beauty } \\
\text { Expert Name }\end{array}$} & $\begin{array}{l}\text { Number of } \\
\text { Respondents }\end{array}$ & $\begin{array}{l}\text { Clinical } \\
\text { Trials }\end{array}$ \\
\hline 1 & dr.Annisa & $\begin{array}{c}15 \\
\text { Responden }\end{array}$ & $75,55 \%$ \\
\hline 2 & $\begin{array}{l}\text { Septi Yuni } \\
\text { Rohana }\end{array}$ & & $80,00 \%$ \\
\hline 3 & dr.Dian & & $85,18 \%$ \\
\hline \multicolumn{2}{|l|}{ Averages } & $80,24 \%$ \\
\hline
\end{tabular}

Based on clinical trial research data, with date water toner above, it obtained a value of $80.24 \%$, so in this clinical trial it was found that date water is very suitable for use by the public to brighten dry skin 


\section{CONCLUSION}

The date water toner product contains 239,327 $\mathrm{mg} / 1000 \mathrm{mg}$ of vitamin $\mathrm{C}$ and a total antioxidant status with a result of $22,096 \mathrm{mg} / \mathrm{mL}$, the category is suitable for testing in the Biology laboratory. The toner product for brightening dry skin made from date water is declared very feasible based on sensory tests because the product has a clear color with a liquid texture that is not too thick and has an odorless aroma, a preference test. After all, it is given convenience when applying it to the customer's facial skin and the face becomes brighter. so that it is in demand by the public and clinical trials for application to facial skin that look bright and not dull because of the natural category in the manufacture of products to lighten dry skin.

\section{REFERENCES}

[1] Dayang J.F, R. d. (2014). Nutritional, Socioeconomic, And Health Benefits Of Dates . International Jounal Of Food, 63.
[2] Syifa, A. Y. A. 2019 Effect of Ajwa Date Extract Mask (Phoenix dactylifera) On Clinical Improvement of Acne Vulgaris (Doctoral dissertation, Sultan Agung Islamic University).

[3] Bayyinah. 2011. Penyegar (Toner). Jakarta: UIN Syarif Hidayatullah.

[4] Pangaribuan, L. (2017). Cosmetic Side Effects and Their Treatment for Women. Prosperous Healthy Family, 20-23.

[5] Elfita, S. Y. 2019. Traditional Broccoli Mask for Dry Facial Skin Care. Jurnal Kapita Selekta Geografi, 120-121.

[6] Sitorus, D. R. 2019. Selection of Facial Wash For Oily Facial Skin With Promethee II Method. Journal Of Computer Engineering, System, and Science, 222.

[7] Sugiyono, P. D. 2012. Statistika Untuk Research. Bandung: Alfabeta Bandung

[8] Permatasari, N. A. (2017). Effect of Ajwa Date Fruit Meat Extract Lotion (Phoenix dactylifera) On The Amount of Sunburn CELL Experimental Study Against Mice Skin BALB/c yang dipapar UVB. 68 . 